\title{
Platelet rich plasma (PRP) induces autophagy in osteoblast precursor 3T3-L1
}

\author{
Sergio Andrés CARMinATI ${ }^{1,2}$, María Carolina BARBOSA ${ }^{2}$; Claudio Marcelo FADER ${ }^{1,2 *}$ \\ 1 Universidad Nacional de Cuyo, Facultad de Odontología, Mendoza, Argentina \\ 2 Consejo Nacional de Investigaciones Científicas y Técnicas (CONICET). Instituto de Histología y Embriología (IHEM), Facultad de Ciencias Médicas, Universidad Nacional de Cuyo, \\ Mendoza, Argentina
}

Key words: Autophagy, 3T3-L1, Platelet rich plasma, Odontology

\begin{abstract}
Autophagy is an essential cellular homeostatic mechanism by which intracellular components are delivered into the lysosomes for degradation and recycling. Autophagy has been related with a diversity of pathological or physiological dentary processes such as bone remodeling, skeletal aging, osteoclastogenesis, osteoblastogenesis and different types of oral cancer. Platelet-rich plasma (PRP), isolated from autologous blood, is a plasma preparation containing a higher concentration of platelets which contains numerous different growth factors and cytokines that activate several cellular signaling cascades. The purpose of this study is to investigate the effect of PRP on autophagy stimulation in both osteoblast precursor 3T3-L1 and non-related osteoblastic cells. Our results showed that PRP can increase the number of autophagic structures in 3T3-L1 and HeLa (cervical cancer cells) cells. Moreover, we have determined by Western blot a rise in the lipidated form of the autophagic protein LC3 (i.e. LC3-II) upon PRP treatment. Taken together, our results suggest that PRP is able to induce a strongly autophagy response in osteoblast precursor and, to a lesser extent, in non-related osteoblastic cells, suggesting that PRP could be a potential therapeutic tool for some autophagy-related diseases associated with bone homeostasis.
\end{abstract}

Bone homeostasis is a tightly controlled mechanism in which osteoblasts (OB, the cells responsible for bone formation), osteoclasts (OC, the cells specialized for bone resorption) and osteocytes (the multifunctional mechanosensing cells embedded in the bone matrix), are the main actors in bone remodeling (Raggatt et al., 2010).

Osteoblast and adipocytes are originated from common mesenchymal stem cells (MSCs), and several transcription factors control the differentiation of the two lineages (Kandel et al., 1999; Prockop, 1997). Other reports have shown that 3T3-L1 cells, an immortalized preadipocyte cell line (Green et al., 1974), are able to differentiate into bone-forming osteoblasts by transdifferentiation. This differentiation produces an increase of alkaline phosphatase (ALP) activity and expression of osteocalcin (OC), bone sialoprotein (BSP), and osterix (Osx) with the formation of mineralized matrix (Justesen et al., 2004; Xie et al., 2014; Takahashi, 2011). These data indicate that 3T3-L1 cells are a good model to study the molecular mechanisms of osteoblast function and differentiation.

${ }^{\star}$ Address correspondence to: Claudio M. Fader,

cfader@fcm.uncu.edu.ar
Macroautophagy (hereafter, autophagy) is a lysosomal catabolic event which is implicated in the turnover and clearance of cytoplasmic components in healthy and damaged tissue via a lysosomal pathway (Eskelinen et al., 2009; Knecht et al., 2009; Mizushima et al., 2008). This process has been involved in tissue regeneration and recycling of key molecules in cell metabolism. Autophagy has been related with a diversity of physiological processes such as innate and adaptive immunity, inflammation, apoptosis, cell differentiation and maturation, thus potentially influencing the associated pathological processes. Moreover, several works have indicated the important role of autophagy in bone homeostasis. It has been reported that autophagy suppression in osteocytes produces a diminishment in bone mass and bone turnover in mice, resulting in an aging-like process in bone tissue and skeleton (Onal et al., 2013). Moreover, several studies have demonstrated that impaired autophagy in osteoblast leads to an osteoporotic-like phenotype (Onal et al., 2013; Nollet et al., 2014). A recent study has shown that Atg7 is needed during osteoblastic cell differentiation, indicating the important role of autophagy in this process (Ozeki et al., 2016). Moreover, genetic or pharmacological inhibition of autophagy suppresses mesenchymal stem cell differentiation to OB. Moreover, autophagy inhibition in 
osteocytes results in a reduced bone volume (Onal et al., 2013). Furthermore, autophagy inhibition leads to a severe decrease in the efficiency of OB function in vitro (DeSelm et al., 2011; Chung et al., 2012). In addition, several works have shown a link between autophagy and some secretion processes, where one of the $\mathrm{OB}$ functions is the extracellular matrix production (Manjithaya et al., 2011; Deretic et al., 2012; Nollet et al., 2014). In this context, autophagy has another crucial role in the control of the $\mathrm{OB}$ to $\mathrm{OC}$ cell ratio, and therefore, in bone remodeling, regulating the bone cell survival/apoptosis (Nollet et al., 2014).

A

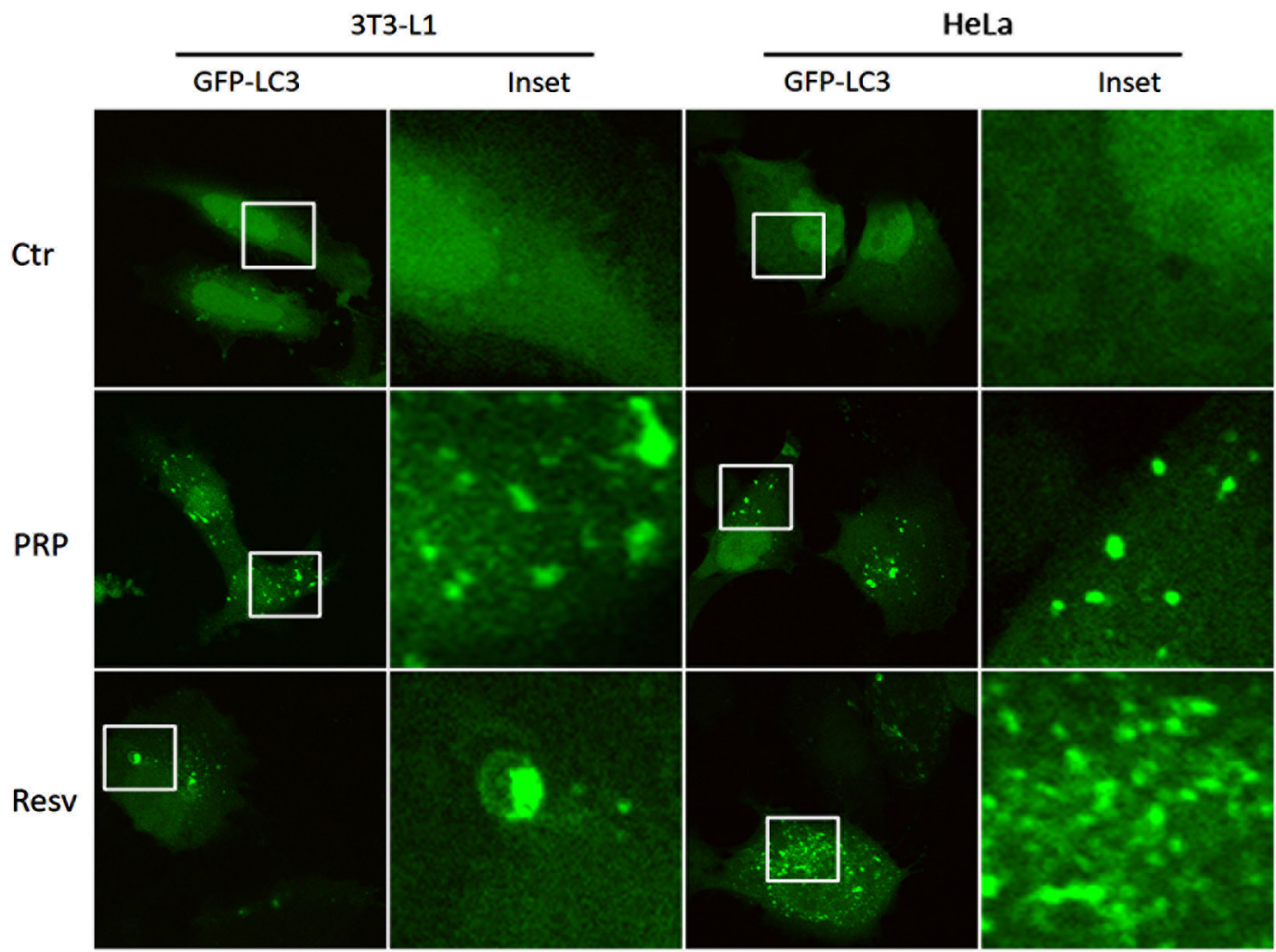

B

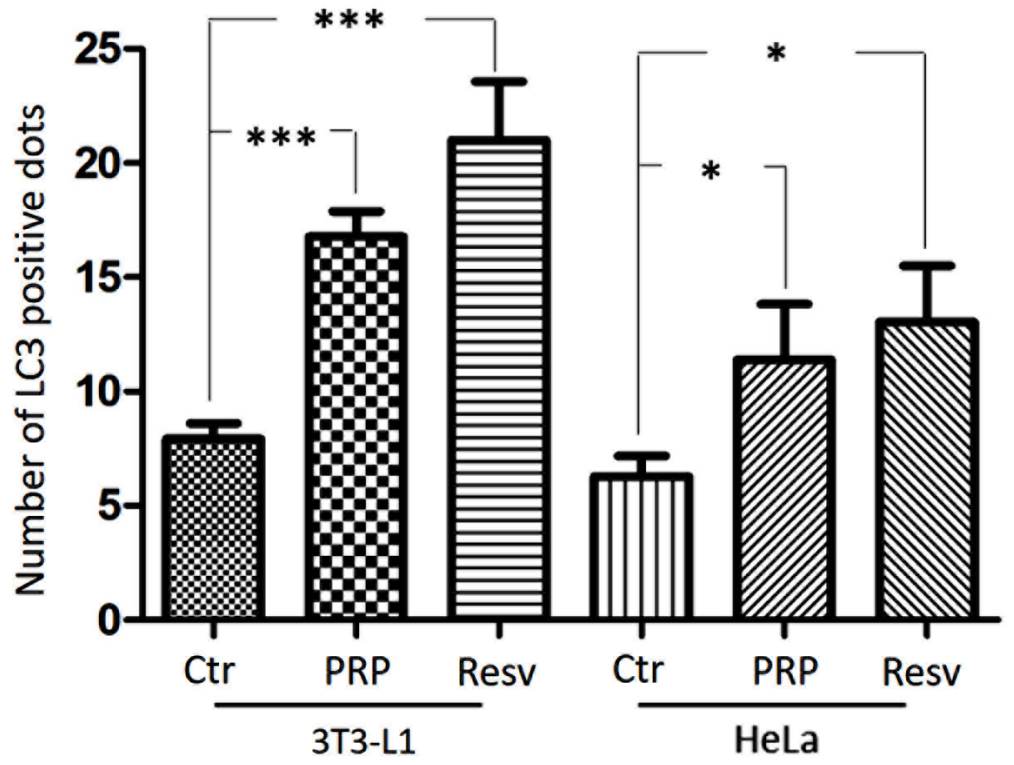

FIGURE 1. PRP induces autophagy in 3T3-L1 and HeLa cells. 3T3-L1 or HeLa cells were incubated in D-MEM medium with $10 \%$ bovine fetal serum at $37^{\circ} \mathrm{C}$ and $5 \% \mathrm{CO}_{2}$. Then, cells were transfected with GFP-LC3 and $24 \mathrm{~h}$ later incubated in absence (Ctr) or presence of $10 \mu \mathrm{l}$ of PRP or $50 \mu \mathrm{M}$ of resveratrol (Positive control) for $4 \mathrm{~h}$ at $37^{\circ} \mathrm{C}$. (A) Images were obtained by confocal microscopy. (B) The percentage of LC3-positive vesicles was measured from images as those displayed in (A). 

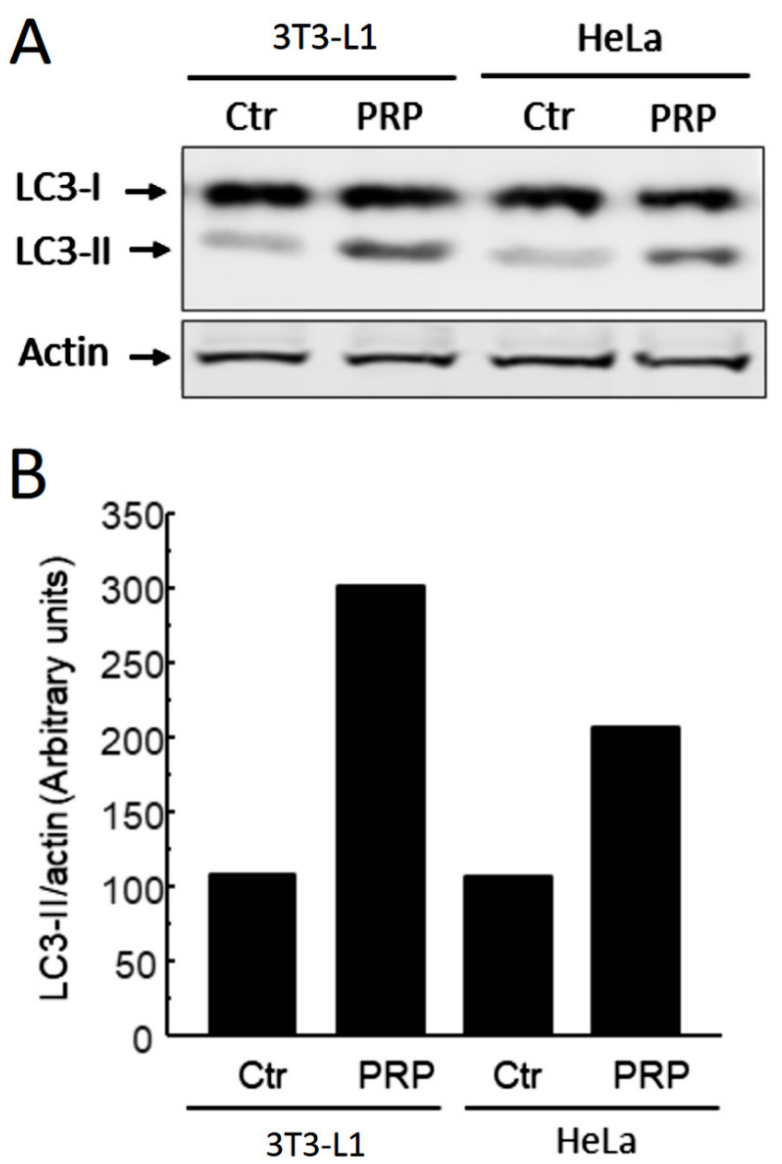

FIGURE 2. Western blot analysis. (A) Samples were subjected to SDS-PAGE and transferred onto a nitrocellulose membrane. The membrane was incubated with a mouse anti-LC3 and the corresponding horseradish peroxidase (HRP)-labeled secondary antibodies and subsequently developed with an enhanced chemiluminescence detection kit. (B) Quantifications of relative optic density (arbitrary units) were made using ImageJ software.

Platelet-rich plasma (PRP), isolated from autologous blood, is a plasma preparation containing a higher concentration of platelets (Everts et al., 2006; Marx, 2004). The platelets secrete multiple kinds of growth factors such as platelet-derived growth factor (PDGF), insulin-like growth factor (IGF), transforming growth factor $\beta$ (TGF- $\beta$ ), basic fibroblast growth factor, and vascular endothelial growth factor (Xie et al., 2014; Foster et al., 2009), which provide unique abilities to promote wound healing and enhance osteogenesis. Due to the repertoire of cytokines, PRP might accelerate different biological processes such as endothelial, epithelial and epidermal regeneration, enhancement of collagen synthesis, stimulation of angiogenesis and enhancement of the hemostatic response to injury. For this reason, PRP has an extremely broad range of clinical healing applications in head, neck, oral and maxillofacial surgery as well periodontics among others (Smith et al., 2007; Laudy et al., 2015). Interestingly, a very recent report has shown that PRP exhibits a chondroprotective effect via the modulation of autophagy in chondrocytes, suggesting that PRP is able to induces autophagy in some cell types (Yang et al., 2018). In this context, the present report aimed to show whether PRP was able to induce autophagy in osteoblast precursors 3T3-L1 cells.

In this experiment, PRP was prepared from $5 \mathrm{ml}$ of whole blood from a forty years old male. Blood coagulation was inhibited by the addition of $3.8 \%$ sodium citrate. The anticoagulated blood was centrifuged at a speed of $1000 \mathrm{rpm}$ for $10 \mathrm{~min}$. The top plasma layer was carefully collected and then centrifuged at a speed of $3000 \mathrm{rpm}$ for $10 \mathrm{~min}$. The supernatant was discarded, and precipitated platelets were resuspended to obtain $1 \mathrm{ml}$ of PRP. Thrombin (1000 U in 10\% $\mathrm{CaCl}_{2} ; 9: 1$ ) was added to PRP and then incubated at $37^{\circ} \mathrm{C}$ in a humidified atmosphere containing $5 \% \mathrm{CO}_{2}$ for $30 \mathrm{~min}$. After incubation, the sample was centrifuged at $4000 \mathrm{rpm}$.

In order to address whether PRP was able to induce autophagy, embryonic rat cells (3T3-L1) or fibroblastic human cancer cells (HeLa) were grown in glass coverslips in 6-well dishes and incubated in D-MEM medium supplemented with $10 \%$ bovine fetal serum, at $37^{\circ} \mathrm{C}$ and $5 \%$ $\mathrm{CO}_{2}$. Then, cells were transfected with the autophagosomal marker protein GFP-LC3 and were incubated 24h later, either in absence (Ctr) or presence of $10 \mu \mathrm{l}$ of PRP or 50 $\mu \mathrm{M}$ of resveratrol (an autophagy inductor) for $4 \mathrm{~h}$ at $37^{\circ} \mathrm{C}$. A population of each cell type was analyzed by confocal microscopy. Interestingly, 3T3-L1 cells incubated in the presence of PRP presented an increased number of GFP-LC3 structures (autophagic vesicles), compared with the control condition (Fig. 1A). PRP also induced autophagy in HeLa cells to a lesser extent than in 3T3-L1 (Fig. 1A). The number of GFP-LC3 positive structures was quantified (Fig. 1B).

Autophagy stimulation causes an increased amount of the lipidated LC3 form that can be assessed by Western blot (Tanida et al., 2005). Thus, the level of processed LC3-II form was analyzed in cells incubated in the conditions mentioned before. As expected, an increased amount of the LC3-II form was observed in both HeLa and 3T3-L1 cells incubated in the presence PRP, being the level of lipidated LC3 lesser in HeLa cells than in 3T3-L1 cells (Figs. 2A and 2B). Taken together, our results suggest that PRP induces a stronger autophagy process in 3T3-L1 cells than in HeLa cells.

Bone regeneration requires the complex and wellorganized process of bone formation (Dimitriou et al., 2011). Several works have shown that autophagy plays an important role in bone cells, participating in both bone homeostasis and bone cell differentiation (Hocking et al., 2012). Our results showed that PRP is able to induce autophagy, increasing the number of autophagic structures and the level of lipidated LC3 in osteoblast precursor cells and non-related osteoblastic cells. In agreement with our results, another two groups have shown that PRP can stimulate autophagy in chondrocytes, contributing to cartilage repair and regeneration (Moussa et al., 2017; Yang et al., 2018). These data allow us to speculate that autophagy induction by PRP could favor the differentiation or functionality of the osteoblast precursors.

In clinical fields, bone tissue regeneration has been a crucial part of regenerative medicine, where PRP has been widely used in orthopedics, dental, periodontal, cosmetic and maxillofacial surgery due to its beneficial effects in tissue repairment (Kon et al., 2009; Lopez-Vidriero et al., 2010; Caramés et al., 2010, 2015). As mentioned before, autophagy has been related with a diversity of physiological 
processes such as formation of mineralized matrix, where its perturbation can lead to many pathologies including osteoporosis and osteoarthritis. For these reasons, understanding the action of autophagy modulators such as PRP, could lead to feasible, new therapeutic approaches against bone disease.

\section{Acknowledgement}

We thank Alejandra Medero for her excellent technical assistance with tissue culture. This work was partly supported by grants from Agencia Nacional de Promoción Científica y Tecnológica (PICT 2013-2335), and SeCTyP K013 (Universidad Nacional de Cuyo) to Claudio M. Fader.

\section{References}

Caramés B, Olmer M, Kiosses WB, Lotz MK (2015). The relationship of autophagy defects to cartilage damage during joint aging in a mouse model. Arthritis \& Rheumatology 67: 1568-1576.

Caramés B, Taniguchi N, Otsuki S, Blanco FJ, Lotz M (2010). Autophagy is a protective mechanism in normal cartilage, and its aging-related loss is linked with cell death and osteoarthritis. Arthritis \& Rheumatism 62: 791-801.

Chung Y, Yoon S, Choi B, Sohn DH, Yoon K, Kim W, Kim D, Chang E (2012). Microtubule-associated protein light chain 3 regulates cdc42-dependent actin ring formation in osteoclast. The International Journal of Biochemistry \& Cell Biology 44: 989-997.

Deretic V, Jiang S, Dupont N (2012). Autophagy intersections with conventional and unconventional secretion in tissue development, remodeling and inflammation. Trends in Cell Biology 22: 397-406.

DeSelm CJ, Miller BC, Zou W, Beatty WL, van Meel E, Takahata Y, Klumperman J, Tooze SA, Teitelbaum SL, Virgin HW (2011). Autophagy proteins regulate the secretory component of osteoclastic bone resorption. Developmental Cell 21: 966-974.

Dimitriou R, Jones E, McGonagle D, Giannoudis PV (2011). Bone regeneration: current concepts and future directions. $B M C$ Medicine 9: 66

Eskelinen E, Saftig P (2009). Autophagy: A lysosomal degradation pathway with a central role in health and disease. Biochimica et Biophysica Acta (BBA)-Molecular Cell Research 1793: 664-673.

Everts PAM, Knape JTA, Weibrich G, Schönberger JPAM, Hoffmann J, Overdevest EP, Box HAM, van Zundert A (2006). Plateletrich plasma and platelet gel: A review. Journal of ExtraCorporeal Technology 38: 174-187.

Foster TE, Puskas BL, Mandelbaum BR, Gerhardt MB, Rodeo SA (2009). Platelet-rich plasma. American Journal of Sports Medicine 37: 2259-2272.

Green H, Meuth M (1974). An established pre-adipose cell line and it's differentation in culture. Cell 3: 127-133.
Hocking LJ, Whitehouse C, Helfrich MH (2012). Autophagy: a new player in skeletal maintenance? Journal of Bone and Mineral Research 27: 1439-1447.

Justesen J, Pedersen SB, Stenderup K, Kassem M (2004). Subcutaneous adipocytes can differentiate into bone-forming cells in Vitro and in Vivo. Tissue Engineering 10:381-391.

Kandel ER, Pittenger C (1999). The past, the future and the biology of memory storage. Philosophical Transactions of the Royal Society B: Biological Sciences 354: 2027-2052.

Knecht E, Aguado C, Cárcel J, Esteban I, Esteve JM, Ghislat G, Moruno JF, Vidal JM, Sáez R (2009). Intracellular protein degradation in mammalian cells: recent developments. Cellular and Molecular Life Sciences 66: 2427-2443.

Kon E, Filardo G, Delcogliano M, Lo Presti M, Russo A, Bondi A, Di Martino A, Cenacchi A, Fornasari PM, Marcacci M (2009). Platelet-rich plasma: New clinical application: A Pilot study for treatment of Jumper's knee. Injury 40: 598-603.

Laudy ABM, Bakker EWP, Rekers M, Moen MH (2015). Efficacy of platelet-rich plasma injections in osteoarthritis of the knee: A systematic review and meta-analysis. British Journal of Sports Medicine 49: 657-672.

Lopez-Vidriero E, Goulding KA, Simon DA, Sanchez M, Johnson DH (2010). The use of platelet-rich plasma in arthroscopy and sports medicine: optimizing the healing environment. Arthroscopy: The Journal of Arthroscopic \& Related Surgery 26: $269-278$.

Manjithaya R, Subramani S (2011). Autophagy: A broad role in unconventional protein secretion? Trends in Cell Biology 21: $67-73$.

Marx RE (2004). Platelet-rich plasma: Evidence to support its use. Journal of oral and maxillofacial surgery, 62: 489-496.

Mizushima N, Levine B, Cuervo AM and Klionsky DJ (2008). Autophagy fights disease through cellular self-digestion. Nature 451: 1069-1075.

Moussa M, Lajeunesse D, Hilal G, El Atat O, Haykal G, Serhal R, Chalhoub A, Khalil C, Alaaeddine N (2017). Platelet Rich Plasma (PRP) induces chondroprotection via increasing autophagy, anti-inflammatory markers, and decreasing apoptosis in human osteoarthritic cartilage. Experimental Cell Research 352: 146-156.

Nollet M, Santucci-Darmanin S, Breuil V, Al-Sahlanee R, Cros C, Topi M, Momier D, Samson M, Pagnotta S, Cailleteau L, Battaglia S, Farlay D, Dacquin R, Barois N, Jurdic P, Boivin G, Heymann D, Lafont F, Lu SS, Dempster DW, Carle GF, Pierrefite-Carle V (2014). Autophagy in osteoblasts is involved in mineralization and bone homeostasis. Autophagy 10: 1965-1977.

Onal M, Piemontese M, Xiong J, Wang Y, Han L, Ye S, Komatsu M, Selig M, Weinstein RS, Zhao H, Jilka RL, Almeida M, Manolagas SC, O’Brien CA (2013). Suppression of autophagy in osteocytes mimics skeletal aging. Journal of Biological Chemistry 288: 17432-17440. 